\title{
Older men's satisfaction (or dissatisfaction) with health care delivery in St Catherine, Jamaica
}

This article was published in the following Dove Press journal:

Patient Intelligence

24 August 2010

Number of times this article has been viewed

\author{
Paul A Bourne' \\ Chloe Morris' \\ Christopher AD Charles ${ }^{2}$ \\ Maureen D Kerr-Campbell ${ }^{3}$ \\ Denise Eldemire-Shearer' \\ 'Department of Community Health \\ and Psychiatry and ${ }^{2}$ King Graduate \\ School, Monroe College, Bronx, and \\ Center for Victim Support, Harlem \\ Hospital Center, New York; ${ }^{3}$ Systems \\ Development Unit, Main Library, \\ Faculty of Humanities and Education, \\ The University of the West Indies, \\ Mona, Jamaica
}

\begin{abstract}
Patient satisfaction and quality of life are becoming increasingly important among the more traditional clinical outcomes in the monitoring and evaluation of health care delivery. This study explored patient's self-rated health and patient satisfaction with health care providers, and examined whether health care providers are a barrier to patient care. The sample consisted of 2000 men aged 55 years and older in the parish of St Catherine, Jamaica. A 132-item questionnaire was used to collect the data. Descriptive statistics was used to provide information about their satisfaction with the health care system. Seventy-four percent of the sample indicated good self-rated health status (excellent, 19.0\%). Forty-seven percent of the sample had sought advice from a health care provider in the last 12 months; $14.1 \%$ understood the advice of the clinician, community health aide $(19.9 \%)$, pharmacist $(15.4 \%)$, nurse $(2.1 \%)$ and nurse aide (4.6\%). The respondents indicated that community health aides contributed more to improving their health (43.4\%) when compared with nurses (34.8\%), clinicians $(17.5 \%)$, and herbalists (3.7\%). Furthermore, $31.7 \%$ indicated that their medical doctors were hospitable and $4.2 \%$ were knowledgeable. Negative self-rated health, perceived lack of knowledge among doctors, lack of understanding of advice from health care providers, are just some of the factors associated with dissatisfaction of patients with chronic conditions. These findings provide a framework and foundation from which further studies on effective intervention aimed at improving the health care provider-patient relationship and service can be conducted.
\end{abstract}

Keywords: satisfaction, men, patient satisfaction, health care provider

\section{Introduction}

Jamaica is a developing country that has an estimated population of 2.7 million people, of whom $49 \%$ are males and almost $11 \%$ are aged 60 years or older. ${ }^{1}$ Life expectancy for males in Jamaica in 1879-1882 was 37.02 years and 39.80 years for females, and in 2002-2004 male life expectancy had risen to 71.26 years and 77.07 years for females. This is clearly an indicator of demographic aging. ${ }^{1}$ Despite females living longer on average than males, men continue to report less illness than women. ${ }^{2,3}$ The increased life expectancy for both genders is a result of improved sanitation, water quality, public health intervention, and deliverables in the health care sector. In spite of the aforementioned variables accounting for increased life expectancy of men and women, health care utilization by men has always been less than by women. Thus, health care utilization is a feminized phenomenon, ${ }^{3}$ and this is equally so among middle-aged and older men.

Jamaica's health system is well supported to meet the needs of the medical services of its society. The health sector of Jamaica is organized into privately and publicly
Correspondence: Paul A Bourne Department of Community Health and Psychiatry, The University of the West Indies, Mona, Jamaica Mobile 8764576990

Email paulbournel@yahoo.com.
(C) 2010 Bourne et al, publisher and licensee Dove Medical Press Ltd. This is an Open Access article which permits unrestricted noncommercial use, provided the original work is properly cited. 
owned institutions. Most of the health care institutions offering ambulatory care are privately owned. Private sector health services are provided through an extensive network of professionals offering specialist services, and by family doctors throughout the island. A number of nongovernmental organizations provide health services for a nominal fee. ${ }^{2}$

The hospitals and the preventive institutions are mainly in the public sector. "The health system offers primary, secondary, and tertiary care. Ambulatory care at the community level is delivered through a network of 343 health centers. Secondary and tertiary cares are offered via 23 government hospitals and the teaching hospital of the University of the West Indies, with a combined capacity of 4,802 beds". ${ }^{3}$ Hospitals are classified into categories A, B, C, and specialist, depending on the level of complexity of the services offered. There are three Type A hospitals, four Type B hospitals, 11 Type $\mathrm{C}$ hospitals, and six specialist hospitals. Type A hospitals are mostly situated in urban areas, and provide inpatient and outpatient services, as well as support referrals from types B and C facilities (found in rural areas), of which there are currently 11 in the country. There are currently six specialist hospitals. ${ }^{3}$ Approximately $38 \%$ of the population utilizes the public sector for ambulatory care, $57 \%$ uses the private sector, and $5 \%$ uses both sectors. ${ }^{3}$

Modern health care systems in Jamaica are seeking to adopt a more client-oriented approach to the delivery of health care. With this paradigm shift, patient satisfaction and quality of life are becoming increasingly important among the more traditional clinical outcomes in the monitoring and evaluation of health care delivery. ${ }^{4}$ Furthermore, patient acceptance and satisfaction with care has only recently received attention in the medical literature. ${ }^{5}$ Satisfaction of users of health care services is a quality-of-care indicator employed to evaluate healthcare and to identify, from the user perspective, aspects of services that can be improved; it also serves as a method to conduct comparative analyses of health care programs. ${ }^{6,7}$ Satisfaction is multifaceted, and reflects the experiences, expectations, and preferences of users with regard to different components of the health care process, such as access, facilities available, interpersonal relationships, and technical quality. Satisfaction is influenced by user characteristics including gender, age, socioeconomic status, and comorbidity, and by the outcomes achieved by health care, principally expectation fulfillment. ${ }^{8,9}$ In addition, satisfaction has an effect on user behavior. Specifically, individuals who are satisfied with their health care are more likely to comply with treatment regimens and be more willing to continue visiting the same doctor in the same institution. ${ }^{10,11}$
Patient satisfaction is usually assessed from questions designed to measure satisfaction with services provided at health care facilities and by all categories of staff (clinicians, nursing personnel, and allied health care staff ). ${ }^{12}$

In both developed and developing countries, the incidence and prevalence of chronic diseases is showing a steady increase, and Jamaica is also facing a growing demand for care of patients with chronic conditions. ${ }^{13}$ The Jamaican government has been undertaking various steps to reform its health care system. Some of them include decentralization, integration of services, setting quality assurance standards, better cost-sharing, improvement of efficiency, fostering of public-private partnerships, and equity. The main agenda behind these reforms is that the health care services provided should better match the current demands of the Jamaican people and should make the available resources much more efficient. The ultimate goal of health services in Jamaica is to improve and maintain the health and functional capacity of the population served. ${ }^{13}$

With the increase in demand from patients who value patient-centered doctors, together with the rise of consumerism in medicine, health service research on the doctor-patient relationship has become an important area of interest for both medical researchers and administrators alike. The satisfaction of patients in developing countries, such as Jamaica, is an unexplored area. Josephs and Nichols examined patient satisfaction and quality of life among persons attending chronic disease clinics in South Trinidad. ${ }^{14}$ They found that approximately two-thirds of participants gave health and support staff a rating of good to excellent; $53.5 \%$ and $58 \%$ gave a poor to fair rating for length of waiting time and explanation offered when there was a significant delay in the starting times of clinics, respectively. ${ }^{14}$

Gender comparative studies reveal that men are less likely than women to go to the doctor for physical and mental health problems and to have a usual place of health care. ${ }^{15,16}$ It is with this understanding that the authors sought to explore patients' self-rated health and satisfaction among middle-aged and older men in the parish of St Catherine, Jamaica. The study also aimed to determine what, if any, correlation exists between self-rated health, employment, and life satisfaction, and also between income of respondents and their satisfaction with health care providers.

\section{Methods}

\section{Sample}

The current study is based on the dataset taken from a survey that was conducted in 2007 of older men (aged at 
least 55 years) in St Catherine, Jamaica. A representative sample of St Catherine was drawn, and a stratified multistage probability sampling technique was used to draw a sample of 2000 respondents.

The Statistical Institute of Jamaica (STATIN) maintains a list of enumeration districts (ED) or census tracts. The parish of St Catherine was chosen because previous data and surveys by STATIN suggested that it has a mix of demographic characteristics (urban, rural, and age composition) which is representative of Jamaica. The parish of St Catherine is divided into a number of electoral constituencies made up of a number of ED. The ED in the parish of St Catherine provided the sampling frame, and the sample size was determined with the help of STATIN. The 162 ED in the parish of St Catherine provided the sampling frame. The ED were listed and numbered sequentially, and selection of clusters was arrived at by use of a sampling interval. Forty ED (clusters) were subsequently selected, with the probability of selection being proportional to population size. Using STATIN and C-Survey computer software, it was determined that 50 older men in each ED would be interviewed, yielding a sample size of 2000 .

The parish of St Catherine had approximately 233,052 males (preliminary census data for 2001), of which number 33,674 males were aged $\geq 55$ years. STATIN maintains maps with ED or census tracts which include the selected ED and access routes, and have references to the selected site of a starting point household within each ED. The starting point was determined by randomly selecting a household with a man aged $\geq 55$ years from the list of persons in the ED. The requisite number of interviews for each ED was completed.

Where the selected household was found to be subsequently devoid of an older man (due to outmigration or death), an adjacent household was canvassed. Where households had a man 55 years and older as a resident and he was not at home, the interviewer returned within two days. In households where there was more than one man $\geq 55$ years, all were included in the survey.

\section{Instrument}

A 132-item questionnaire was used to collect the data. The instrument was subdivided into general demographic profile of the sample, past and current health status, healthseeking behavior, retirement status, and social and functional status. The overall response rate for the survey was $99 \%$ ( $\mathrm{n}=1983$ ). Data were stored, retrieved, and analyzed using SPSS for Windows, version 16.0 (SPSS Inc., Chicago, IL).
The questionnaire was subsequently developed to collect data for a Doctorate of Philosophy in Public Health for one of the authors. It was pretested for clarity and appropriateness, and any necessary adjustments to be made, by the Health Centre at the Department of Community Health and Psychiatry, The University of the West Indies. The final instrument was formatted into a booklet for easier handling.

\section{Measure}

The variable of happiness was measured based on self-reports of those men interviewed. It was a Likert scale question, ranging from always to rarely happy. The variable of selfrated health status was measured using men's self-rating of their overall health status, ranging from excellent to poor. The question asked was "How would you rate your health today?" The options were excellent (1), good (2), fair (3), and poor (4). In evaluating educational level, the question asked was "What is your highest level of education attained?" The options were no formal education (1), basic schooling (2), primary school/all age (3), secondary/high/technical school (4), vocational, ie, apprenticeship/trade (5), diploma (6), undergraduate degree (7), and post-graduate degree (8). In assessing childhood illness, the question asked was "Were you seriously ill as a child?" The two options were yes (1) and no (2). An additional question was "Were you frequently ill as a child?", for which the options were yes (1) and no (2). If the response to either question was "yes", this was coded as poor childhood health status and if the response was "no" in both cases, it was coded as good health status in childhood. Age was categorized into three subgroups, ie, 55-64 years, 65-74 years, and $\geq 75$ years.

The variable is measured based on self-reported happiness. ${ }^{17-19}$ This operationalization is based on a basic indicator proposed by Diener, ${ }^{20}$ including a more emotional component referring to happiness. The question that was asked was "Taking all things together, how happy would you say you are?".This was a Likert scale question, ranging from high to low happiness. In terms of life satisfaction, Diener $^{20}$ had proposed that happiness includes emotional components and also a more cognitive component referring to life satisfaction, taking into consideration the question "All things considered, how satisfied are you with your life as a whole nowadays?" The variable of health status was measured using self-rated overall health status according to Kahneman and Riis, ${ }^{21}$ ranging from excellent to poor health status. The variable used in this study for health status was a binary one, ie, whether or not the person had good to excellent or poor health status. 
Patient satisfaction was assessed by questions designed to measure satisfaction with services provided, facilities, and staff. Participants were asked to rate quality of health care services, condition of the facility, and performance of categories of staff (ie, doctors, nursing personnel, and community aides) using the Likert scale of excellent, very good, good, moderate, poor, and very poor. The questionnaire covered aspects such as whether or not the respondent had sought medical advice in the previous 12 months, how soon had the respondent sought medical care after the onset of illness, did the respondent understand the advice given by the health care provider, how knowledgeable was the health care provider; and the extent to which the health care provider contributed to improving their health.

\section{Ethical approval}

Ethical approval for this study was given by the University of the West Indies Medical Faculty's Ethics Committee.

\section{Statistical analysis}

For the current study, descriptive statistics were employed to provide background information on the sample, and Chi-square was used to examine nonmetric variables. A $P$ value less than 5\% (two-tailed) was used to indicate statistical significance. There were two exclusion criteria: one, in the event that a variable had more than $20 \%$ of cases missing; and two, collinearity. In addressing collinearity $(r>0.6)$ the aim was to enter variables independently in the model to determine which one should be retained during the final model construction. To retain or exclude a variable from the model, this was based on the variable's contribution to the predictive power of the model and its goodness of fit.

\section{Results}

Table 1 presents the sociodemographic characteristics of the sample. The sample had 2000 men aged 55 years and older. Of those who were employed, the majority were tradesmen (46.8\%) compared with professionals (administrators $24.0 \%$ and technical $14.3 \%$ ), clerks (7.6\%), and service workers (7.3\%). Seventy-four percent of the sample indicated at least good self-rated health status (excellent, 19.0\%). Almost 46\% of the sample had visited a doctor in the last five years $(31.6 \%$ within the previous 12 months, $39 \%$ in $12-35$ months, and $29.4 \%$ in 36 months and over). Only $34.7 \%$ of the sample indicated that they visited a doctor at the onset of an illness. Most of those who sought medical care did so immediately after (52\%), 2-7 days (41.2\%), 1-3 weeks (1.8\%), or four
Table I Sociodemographic characteristics of a sample of Jamaican men aged 55 years and older

\begin{tabular}{|c|c|c|}
\hline Characteristic & $\mathbf{n}$ & $\%$ \\
\hline \multicolumn{3}{|l|}{ Area of residence } \\
\hline Urban & 981 & 49.0 \\
\hline Rural & 1019 & 51.0 \\
\hline \multicolumn{3}{|l|}{ Age cohort (years) } \\
\hline $55-59$ & 469 & 23.4 \\
\hline $60-64$ & 413 & 20.6 \\
\hline $65-69$ & 374 & 18.7 \\
\hline $70-74$ & 345 & 17.3 \\
\hline $75-79$ & 189 & 9.5 \\
\hline$\geq 80$ & 210 & 10.5 \\
\hline \multicolumn{3}{|l|}{ Marital status } \\
\hline Single & 686 & 34.3 \\
\hline Married & 894 & 44.7 \\
\hline Separated & 112 & 5.6 \\
\hline Common law & 136 & 6.8 \\
\hline Widowed & 172 & 8.6 \\
\hline \multicolumn{3}{|l|}{ Head of household } \\
\hline Self & 1763 & 88.2 \\
\hline Partner & 122 & 6.1 \\
\hline Child & 63 & 3.1 \\
\hline Sibling & 36 & 1.8 \\
\hline Other & 16 & 0.8 \\
\hline \multicolumn{3}{|l|}{ House tenure } \\
\hline Own & 824 & 41.2 \\
\hline Other (rent, lease) & 1176 & 58.8 \\
\hline \multicolumn{3}{|l|}{ Employment status } \\
\hline Employed & 524 & 26.2 \\
\hline Unemployed & 412 & 20.6 \\
\hline Retired & 1064 & 53.2 \\
\hline \multicolumn{3}{|c|}{ Monthly income (Jamaican dollars) } \\
\hline$<1000-4999$ & 206 & 39.4 \\
\hline 5000-9999 & 143 & 27.3 \\
\hline $10,000-14,999$ & 90 & 17.2 \\
\hline $15,000-19,999$ & 47 & 9.0 \\
\hline$>20,000$ & 37 & 7.1 \\
\hline \multicolumn{3}{|l|}{ Educational level } \\
\hline No formal & 200 & 10.0 \\
\hline Infant (basic) & 1104 & 55.2 \\
\hline Primary & 557 & 27.8 \\
\hline Secondary & 79 & 3.9 \\
\hline Post-secondary & 37 & 1.9 \\
\hline Tertiary & 23 & 1.2 \\
\hline
\end{tabular}

weeks $(0.9 \%)$ following the onset of an illness, and $0.7 \%$ reported that they had not sought any medical care.

Eighteen percent of respondents had experienced illness during childhood. The medical conditions were measles (34.5\%), asthma (26\%), pneumonia (9.9\%), polio $(8.7 \%)$, accident (6.5\%), jaundice (4.5\%), hernia (1.7\%), and others $(3.1 \%)$. Currently the medical conditions experienced by the respondents in the study were prostate and other cancers (16.8\%), kidney diseases (12.7\%), hypertension (9.2\%), heart disease $(5.3 \%)$, benign prostatic hyperplasia $(7.2 \%)$, diabetes 
mellitus (6.5\%), arthritis (1.0\%), asthma (0.3\%), and others $(5.9 \%)$. Only $34.5 \%$ of the sample had ever undergone a prostate cancer screening examination.

The majority of the sample indicated that they were rarely depressed (56.9\%), 2.5\% were always depressed, and 34.3\% were depressed sometimes. Only $24 \%$ of the respondents were rarely happy, and $4.5 \%$ indicated always. Almost 33\% of the sample was rarely satisfied with life, $3.5 \%$ indicated always, and $33.7 \%$ said sometimes.

Forty-seven percent of the sample had sought advice from a medical provider in the last 12 months, $14.1 \%$ understood the advice of the doctor, community health aide (19.9\%), pharmacist $(15.4 \%)$, nurse $(2.1 \%)$, or nurse aide $(4.6 \%)$. In terms of the level of satisfaction received from health care providers, respondents gave a rating of "very good" for community health aides and pharmacists, while "good" was highest among nurses and medical doctors, who also received a rating of "very poor" (see Figure 1). The respondents indicated that community health aides contributed more to improving their health status (43.4\%) compared with other health care providers (nurses $34.8 \%$, doctors $17.5 \%$, and herbalists $3.7 \%$ ). Six percent of the respondents indicated that they did not like their doctor, $31.7 \%$ indicated that their doctor was hospitable, $4.2 \%$ reported that the their doctor was knowledgeable, $36.4 \%$ reported that the waiting time to see the doctor was too long, and $17.5 \%$ indicated that the physical milieu was poor. Utilization of the health care system by respondents comprised health centers $(32.1 \%)$, private doctors (31.0\%), public hospitals (18.8\%), private hospitals (17.3\%), herbalists $(0.1 \%)$, and health institutions abroad $(0.1 \%)$.

Respondents who were happier and had greater life satisfaction were more likely to have visited a doctor in the previous 12 months (Table 2). Males who resided in rural areas were more dissatisfied with life $(35.9 \%)$ than urban males (29.8\%). Males who owned their own homes (31.3\%) had better self-rated health status compared with those who did not (9.9\%). There was moderate self-rated health status for those who do not own their homes $(36.2 \%)$ and those who owned their own homes $\left(11.4 \% ; \chi^{2}=222.7, P<0.0001\right)$.

There was a significant statistical association between self-rated health status and employment category $\left(\chi^{2}=81.0\right.$, $P<0.0001)$. Respondents who were employed had greater self-rated (excellent) health status $(28.3 \%)$ than those who were unemployed $(8.3 \%)$ or retired $(18.2 \%)$. Furthermore, respondents who had secondary or postsecondary (42.1\%) and tertiary (35.1\%) level education had higher self-rated health status than those without formal $(17.7 \%)$ and primary (17.3\%) education $\left(\chi^{2}=88.4, P<0.0001\right)$.

There was a significant statistical relationship between satisfaction and income category of respondents (Table 3 ). Respondents in the low-income category were more satisfied with the service of doctors and nurse aides, while respondents in the high-income category were more satisfied with community aides and pharmacists.

\section{Discussion}

This study found that approximately half of the respondents had visited a doctor in the previous five years compared with less than one-third in the last 12 months and approximately two-fifths in the previous 12-35 months. Furthermore, respondents aged 55 years and older indicated that they had mostly noncommunicable diseases, such as prostate and other cancers, kidney disease, hypertension, heart disease, benign prostatic hyperplasia, diabetes mellitus, and arthritis.

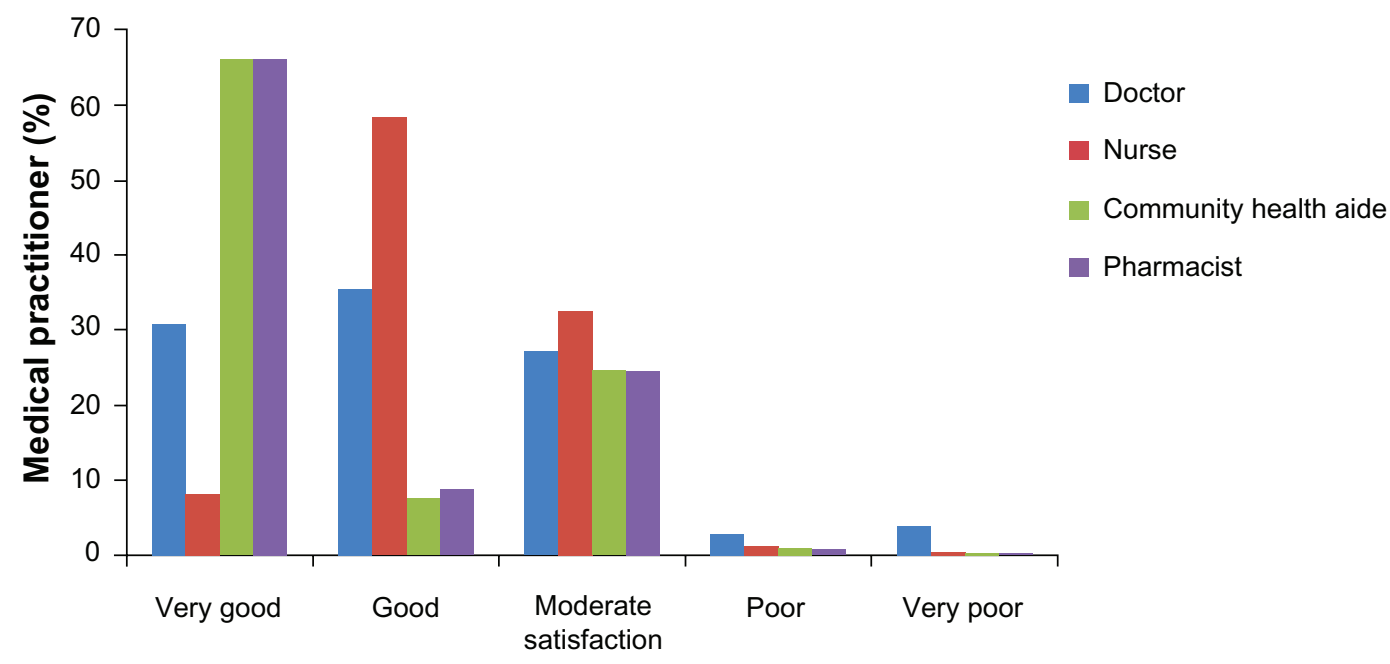

Figure I Satisfaction with service delivery of health care providers. 
Table 2 Health care seeking behavior according to life satisfaction and happiness

\begin{tabular}{|c|c|c|c|c|}
\hline \multirow[t]{2}{*}{ Characteristic } & \multicolumn{4}{|c|}{ Life satisfaction' } \\
\hline & $\begin{array}{l}\text { Rarely } \\
\text { n (\%) }\end{array}$ & $\begin{array}{l}\text { Sometimes } \\
\text { n (\%) }\end{array}$ & $\begin{array}{l}\text { Most times } \\
\text { n (\%) }\end{array}$ & $\begin{array}{l}\text { Always } \\
\text { n (\%) }\end{array}$ \\
\hline \multicolumn{5}{|l|}{ Doctor's visit } \\
\hline Less than 12 months & $89(29.3)$ & $81(26.3)$ & $102(39.1)$ & I7 (4I.5) \\
\hline $12-35$ months & $123(40.5)$ & I $43(46.4)$ & $82(31.4)$ & $8(19.5)$ \\
\hline \multirow[t]{2}{*}{$36+$ months } & $92(30.2)$ & $84(27.3)$ & $77(29.5)$ & $16(39.0)$ \\
\hline & Happiness ${ }^{2}$ & & & \\
\hline \multicolumn{5}{|l|}{ Doctor's visit } \\
\hline Less than 12 months & $60(28.3)$ & $96(27.1)$ & II4 (38.5) & $19(36.5)$ \\
\hline $12-35$ months & $96(45.3)$ & $|5|(42.7)$ & $96(32.4)$ & $13(25.0)$ \\
\hline $36+$ months & $56(26.4)$ & $107(30.2)$ & $86(29.1)$ & $20(38.5)$ \\
\hline
\end{tabular}

Notes: ${ }^{1} \chi^{2}=23.4, P<0.0001 ;{ }^{2} \chi^{2}=19.3 ; P=0.004$.

The level of satisfaction with health care providers and the overall quality of service was fair, although there were aspects of the health care service that was rated from moderate to poor. These findings are consistent with those of other studies showing that patients with chronic conditions were dissatisfied more frequently. ${ }^{22}$ The fact that these were patients with chronic conditions and dissatisfied deserves attention, because they use the health services regularly, and their satisfaction can influence their contribution to their own disease management, which is important for optimal control of their conditions. Patients with chronic conditions receive long-term care and this should be reliable, regular, and coordinated among different health care providers.

In this study, the majority of men indicated that they were rarely depressed, approximately one-third were depressed sometimes, and almost the same number were rarely satisfied with life or sometimes satisfied with life. These results are lower than values obtained for self-rated health status. Approximately three-quarters of the respondents indicated at least good self-rated health status, with approximately one-fifth indicating excellent health. Interestingly, the study showed that men who were happier and had greater life satisfaction were more likely to have visited a doctor in the previous 12 months. Studies have shown that patients with negative self-rated health were at greater risk for dissatisfaction with health care. ${ }^{23}$ Most of the men in this study had chronic noncommunicable diseases, and a chronic condition is related to negative self-rated health and at the same time, patients with such conditions tend to perceive health care as unsatisfactory. ${ }^{24,25}$ Positive self-rated health is related to better functional and physical states. ${ }^{26}$ Therefore, keeping the disease under control in a patient with a chronic condition is crucial for a positive perception of self-rated health. Given that in this study approximately three-quarters of respondents indicated at least good self-rated health status, with approximately one-fifth indicating excellent health, it is possible that there are factors other than their self-rated health status that may have contributed to the low level of satisfaction among respondents. It is possible that there were respondents in this study who had more than one illness, and would be more likely to express their dissatisfaction with the quality of care received from their health care providers. Poor subjective quality of life among persons with multiple illnesses has been found in a number of studies, and suggests the need for regular monitoring and evaluation of those at increased risk for poorer perceived health. These become more important when it is realized that subjective quality of life can predict morbidity and mortality. ${ }^{27-29}$

Some organizational characteristics can cause dissatisfaction among patients. The main problems are related to cleanliness of the facilities and administrative procedures. Nearly one-fifth of the respondents indicated that the physical

Table 3 Patients satisfied with explanation of particular health care provider according to income group

\begin{tabular}{|c|c|c|c|c|c|c|}
\hline \multirow[t]{2}{*}{ Characteristic } & \multicolumn{5}{|c|}{ Income group (Jamaican dollars) } & \multirow[t]{2}{*}{$P$} \\
\hline & $<1000 \%-4999 \%$ & $5000 \%-9999 \%$ & $10,000 \%-14,999 \%$ & $15,000 \%-19,999 \%$ & $>20,000 \%$ & \\
\hline \multicolumn{7}{|l|}{ Satisfied patient with: } \\
\hline Community health aide & 11.9 & 4.2 & 12.2 & 8.5 & 16.2 & $<0.0001$ \\
\hline Nurse & 5.8 & 2.1 & 2.2 & 0.0 & 0.0 & 0.091 \\
\hline Medical doctor & 21.4 & 11.9 & 11.1 & 0.0 & 0.0 & $<0.0001$ \\
\hline Pharmacist & 7.3 & 7.7 & 15.6 & 21.3 & 18.7 & 0.007 \\
\hline
\end{tabular}


milieu was poor and just over one-third indicated that the waiting time to see a doctor was too long. Registration of patients, opening of a clinical chart for a newcomer, and dispensing of medication by pharmacists are all procedures that may take longer than expected and sometimes cause dissatisfaction. Furthermore, health care in Jamaica is free to all citizens and legal residents at government hospitals and clinics, and includes prescription drugs. However, one of the drawbacks to free health care is long time lines with no appointments accepted by physicians. In addition, some rural public hospital and clinics are without their full quota of doctors and other health care providers. In this study, one-third of respondents visited health centers and just under one-fifth visited public hospitals. The long waiting times experienced by some respondents at these public health care institutions may have contributed to their dissatisfaction with the quality of health care offered by the state. This is consistent with reports from other developing countries. ${ }^{30}$ Therefore, attention to both elements, ie, the doctor-patient relationship and organizational arrangements, are essential to improve patient satisfaction. Improvement of the doctorpatient relationship relies heavily on the attitude of doctors, whereas the improvement of organizational arrangements is the responsibility of managers. In this study, we found a positive statistical association between life satisfaction and frequency of doctor's visits, indicating that low satisfaction with health care providers may result in fewer patient visits for health care.

Informing patients about different aspects of their health and about the care they need are very important for those with chronic noncommunicable conditions. Also, treating patients as coparticipants in the process of decision-making has been repeatedly emphasized as an important patient right. ${ }^{31}$ When patients are well-informed and participate in treatment decisions, their anxiety decreases and their therapeutic adherence improves, thus increasing the chances of getting better health outcomes. ${ }^{32}$ Nevertheless, this critical component of communication is badly neglected by doctors. ${ }^{33}$ In a study by Doubova et al one of the most frequent prescription errors in ambulatory patients over 60 years of age with nonmalignant pain syndrome was that family doctors failed to provide instructions to the patients about how to take the prescribed drugs, and did not inform them of possible adverse effects. ${ }^{34}$ From our perspective, close doctor-patient communication is the backbone of health care, and enables the doctor to become familiar with the condition of the patient and to place treatment in a better context and permit more comprehensive disease management. Nevertheless, we found that approximately one-half of respondents had visited a doctor in the previous 12 months and only approximately one-eighth understood the advice given. This was slightly higher for community health aides and pharmacists. It is important to note that many patients did not understand the advice given by nurses or nurse aides. It is also likely that the doctors used technical medical terms and abbreviations which are like a foreign language to many patients, given the context of this study in which only $6 \%$ of the respondents have post-secondary or tertiary education.

Patients have two basic needs at a medical consultation, ie, a need for medical information and instruction, and a need for emotional support and reassurance. ${ }^{35}$ These needs correspond with instrumental behavior for giving information and advice, and affective behavior for showing concern and giving emotional support. ${ }^{36}$ It may be hypothesized that, at first, a patient's uncertainty and anxiety requires emotional support and attention from the doctor, whereas, in subsequent visits, patients might need more medical or technical information to apply treatment effectively. Adequate management of the condition is likely to require doctors to respond to these changing needs accordingly, by shifting their communication style. ${ }^{37}$ In our study, it is likely that doctors failed to give the necessary information to their patients, and this may account for just $4.2 \%$ of doctors being deemed knowledgeable by the respondents. This may affect their subsequent visits to that doctor. Furthermore, it is reported that men in Jamaica have not fully accessed and utilized the health care services provided by the government. ${ }^{38}$ In a Jamaican study by Figueroa et al significantly $(P<0.0001)$ more men $(86 / 463,18.6 \%)$ than women $(40 / 927,4.3 \%)$ had never had their blood pressure taken by a health professional. ${ }^{38}$ In this study, just over one-half of respondents reported that they sought medical care at the onset of illness, while just over two-fifths indicated that they did so within 2-7 days.

Doctors often do not give adequate consideration to the patient's feelings or desires regarding the illness or condition being treated. Patients, on the other hand, often assume a doctor may know things about their condition when he or she actually does not. In a study by Jackson et al involving 500 patients who were seen by 38 primary care clinicians for physical symptoms, aspects of patient-doctor communication, such as receiving an explanation of the symptom cause, likely duration, and lack of unmet expectations, were found to be the key predictors of patient satisfaction. ${ }^{39}$ In this study, most of the respondents reported that the community aides contributed more to improvement in their health and therefore greater satisfaction than nurses and doctors. Furthermore, just 
over three-tenths indicated that their doctors were hospitable. It has been shown that the doctor's attitude towards patients, his or her ability to elicit and respect patients' concerns, provision of appropriate information, demonstration of empathy, and development of patient trust are the key determinants of good compliance with medical treatment in patients. ${ }^{40,41}$

The potency, evaluative, and activity images patient has in mind about their doctors are positively related to their age and the length of time they have been seeing a particular doctor. These images are negatively related to the educational level of the patient. More educated patients do not have as desirable an image of the doctor as do less educated patients. Older patients and those who have been coming to the doctor longer apparently have more desirable images of the doctor than younger or newer patients. Conversely, older patients may have more trouble understanding the doctor than do younger ones. Furthermore, older patients may feel they do not get enough opportunity to communicate with the doctor, especially in the public health care system in Jamaica, where health care centers and hospitals, especially in rural areas, are overcrowded and doctors are unable to spend adequate time with patients. In addition, older patients, like the men in this study, the majority of whom were over 65 years and had less than secondary education, may present more communication-related problems for the doctor than do younger patients. Older patients understand less and are prone to frustration because of this. These older patients seldom feel they get enough chance to talk to the doctor and tell him or her what they want, although they think well of the doctor mentally.

According to Wilks et al ${ }^{42}$ Jamaican males with tertiary education were the least likely to smoke cigarettes or marijuana and take illegal drugs, but were more susceptible to alcohol consumption. They further argued that postsecondary school level males were more likely to use a seat belt when being front-seat passengers in a motor vehicle. Lifestyle practices of educated males contributed to better health than those of less well educated cohorts. ${ }^{42}$ Well educated patients present some specific negatives to the doctor in the process of building a relationship. Presumably, because of their training and reasoning ability, more educated patients can detect flaws and coverups in the doctor's communication with them. They may feel that the doctor is not "leveling" with them. ${ }^{43}$ More educated patients may be able to detect flaws in doctorpatient communication than can less educated patients. This could contribute to patient dissatisfaction. Because of this, the doctor's image suffers, and this increases their dissatisfaction. In this study, approximately $6 \%$ of patients have postsecondary or tertiary education. However, an interesting finding is that respondents in the high-income category were more satisfied with community aides and pharmacists than with doctors and nurses. A high percentage of these persons were skilled professionals and like those who were more educated, were likely to expect more from doctors compared with their low-income counterparts, and hence their likely dissatisfaction.

Approximately one-third of the respondents visited private medical practices, while just over one-sixth visited private hospitals. Doctors, when dealing with patients in the office, will build a stronger, more credible relationship with their patients. Most of these private patients will more likely see the same doctor on subsequent visits, so background information on the patient is very important in the relationship-building process because the doctor may gain credibility over the years and is perceived to communicate better. Patients also think more favorably of the doctor the longer they come to see him or her. How often they see the doctor is unimportant in the relationship, and hence the higher level of satisfaction. ${ }^{6}$ Patients who visit their doctors in private practice and those who visit a private hospital will be likely to spend more time with the doctor compared with those who visit public health institutions. With more time, it is likely that the doctor may communicate better with the patient, laying a firm foundation on which a significant, meaningful, and mutually satisfactory relationship can be built. Therefore, it is likely in this study that more private patients had greater overall satisfaction than public patients.

One of the main shortcomings of this research was that the data were collected by questionnaire rather than by direct measurement of the variables of interest. Perhaps some actual measurements of time spent with the clinician and communication effectiveness would have yielded further results. Despite this limitation, it has been established that surveys and interviews can be utilized successfully in order to ascertain information from patients on health care delivery, attitudes towards health care professionals, areas that need improvement in the health sector, and how to use these responses to improve patient and quality care. ${ }^{44} 46$ Patients are more than lower-level animals in experiments, and so in order to improve their health outcomes effectively, their views are critical in the health care feedback and implementation process. A study by Vingerhoets et $\mathrm{al}^{47}$ found that even after feedback about patients' evaluation of care to their health care providers, there was no change in the evaluation of care received, which challenges the value of using patients' views 
in efforts to improve quality of health care. However, the researchers ${ }^{47}$ considered that using patient evaluation in the feedback process of quality care is but one component, which supports the viewpoint of Wilcock et $\mathrm{al}^{48}$ that patients' views should be incorporated in health care modernization. If the health care industry is genuinely seeking to deliver on its mandate of improving health care and quality of care, quality improvements must be done within the context of incorporating patients' intelligence, satisfaction, and dissatisfaction in health care deliverables.

\section{Conclusion}

There are some interpersonal and organizational situations that reveal dissatisfaction among patients with chronic conditions receiving care from both public and private health care institutions in Jamaica. Negative self-rated health, perceived lack of knowledge on the part of doctors, and lack of understanding of advice from health care providers, are just some of the factors associated with dissatisfaction of patients with chronic conditions, and these are among the factors explaining low patient health care utilization. Based on these findings, there is the need for improved communication between health care providers and patients. Strategies employed should incorporate the ideas or health beliefs of the patient, and go beyond merely giving instructions. Responding to the need for satisfaction in patients with chronic conditions is important in improvement of the quality of the services that are most important to them. Therefore, better management of patients with chronic conditions by doctors is desirable, as are institutional changes that enable doctors to provide longer consultations. Consultancy time must be about communicating with the patient, and not using medical jargon which satisfies the medical profession but fails to reach the patient. The outcome of medical care is the improvement of health and not the utilization of jargon, more healthcare providers and health care facilities that are distant from having a change in unhealthy practices of patients as well as lowing health conditions. This study has shown that patient intelligence has not been taken into account by health care professionals.. Therefore, conducting research in this area may help clinicians, educators, and health service administrators to understand better the doctor-patient relationship and communication that is unique in our culture and social setting. This may provide a framework and foundation from which further studies on effective intervention aimed at improving the doctor-patient relationship can be conducted. This is a particularly important issue for medical doctors and other health care providers.

\section{Disclosure}

The authors declare no conflict of interest in this work.

\section{References}

1. Statistical Institute of Jamaica. Demographic Statistics, 1978-2007. Statistical Institute of Jamaica: Kingston; 1979-2008.

2. Pan American Health Organization. Jamaica - Health in the Americas 2007 - Volume II - Countries. Washington, DC: Pan American Health Organization; 2007.

3. Jamaican Ministry of Health. Annual Report 2004. Kingston: Jamaican Ministry of Health; 2005.

4. Bolus R, Pitts J. Patient Satisfaction: The Indispensable Outcome. [Internet]. Available http://www.managedcaremag.com/archives/9904/9904. patsatis.htm Accessed Mar 25, 2010.

5. Kaplan SH, Greenfield S, Gandek B, Rogers WH, Ware JE. Characteristics of physicians with participatory decision-making styles. Ann Intern Med. 1996;124:497-504.

6. Sitzia J, Wood N. Patient satisfaction: A review of issues and concepts. Soc Sci Med. 1997;45:1829-1843.

7. Jackson JL, Chamberlin J, Kroenke K. Predictors of patient satisfaction. Soc Sci Med. 2001;52:609-620.

8. Lezzoni LI, Davis RB, Soukup J, O'Day B. Quality dimensions that most concern people with physical and sensory disabilities. Arch Intern Med. 2003;163:2085-2092.

9. Wensing M, Grol R, Asberg J, van Monfort P, van Weel C, Feling A. Does the health status of chronically ill patients predict their judgments of the quality of general practice care? Qual Life Res. 1997;6: 293-299.

10. Kincey JA, Bradshaw PW, Ley P. Patient satisfaction and reported acceptance of advice in general practice. J R Coll Gen Pract. 1975;25: 558-566.

11. Larsen DE, Rootman R. Physicians' role performance and patient satisfaction. Soc Sci Med. 1976;10:29-32.

12. Ware JE Jr, Davies-Avery A, Stewart AL. The measurement and meaning of patient satisfaction. Health Med Care Serv Rev. 1978;1:3-15.

13. Category: Health in Jamaica - Jamaica Wiki. [Internet]. Available from: wiki.jamaicans.com/index.php/Category: health in Jamaica. Accessed Mar 25, 2010.

14. Joseph C, Nichols S. Patient satisfaction and quality of life among persons attending chronic disease clinics in south Trinidad, West Indies. West Indian Med J. 2007;56:108-114.

15. Galdas PM, Cheater F, Marshall P. Men and health help-seeking behaviour: Literature review. J Adv Nurs. 2005;49:616-623.

16. Möller-Leimkühler AM. Barriers to help-seeking by men: A review of socio-cultural and clinical literature with particular reference to depression. J Affect Disord. 2002;71:1-9.

17. Easterlin RA. Income and happiness: Towards a unified theory. Economic Journal. 2001;111:465-484.

18. Frey BS, Stutzer A. What can economists learn from happiness research? J Econ Lit. 2002;90:402-435.

19. Borghesi S, Vercelli A. Happiness and health: Two paradoxes. Paper presented at the Conference on "Policies for Happiness" held at the University of Siena. 2007, June 14-17.

20. Diener E. Subjective well-being: The science of happiness and a proposal for a national index. Am Psychol. 2000;55:34-43.

21. Kahneman D, Riis J. Living, and thinking about it, two perspectives. In: Huppert FA, Kaverne B, Baylis N, editors. The Science of Well-being. Oxford: Oxford University Press; 2005.

22. Druss BG, Schlesinger M, Thomas T, Allen H. Chronic illness and plan satisfaction under managed care. Health Aff. 2000;19:203-209.

23. Al-Mandhari AS, Hassan AA, Haran D. Association between perceived health status and satisfaction with quality of care: Evidence from users of primary health care in Oman. Fam Pract. 2004;21:519-527.

24. Hall JA, Milburn MA, Epstein AM. A causal model of health status and satisfaction with medical care. Med Care. 1993;31:84-94. 
25. Westaway MS, Rheeder P, Van Zyl DG, Seager JR. Interpersonal and organizational dimensions of patient satisfaction: The moderating effects of health status. Int J Qual Health Care. 2003;15:337-344.

26. Shooshtari S, Menec V, Tate R. Comparing predictors of positive and negative self-rated health between younger (25-54) and older (55+) Canadian adults: A longitudinal study of well-being. Res Aging. 2007;29:512-554.

27. Westin L, Nilstun T, Carlsson R, Erhardt L. Patients with ischemic heart disease: Quality of life predicts long-term mortality. Scand Cardiovasc J. 2005;39:50-54.

28. Narayan KM, Gregg EW, Fagot-Campagna A, et al. Relationship between quality of diabetes care and patient satisfaction. J Natl Med Assoc. 2003;95:64-70.

29. Singh JA, Nelson DB, Fink HA, Nichol KL. Health-related quality of life predicts future health care utilization and mortality in veterans with self-reported physician-diagnosed arthritis: The veterans' arthritis quality of life study. Semin Arthritis Rheum. 2005;34:755-765.

30. Bernhart MH, Wiadnyana IG, Wihardjo H, Pohan I. Patient satisfaction in developing countries. Soc Sci Med. 1999;48:989-996.

31. Kane R, Deuschle K. Problems in doctor-patient communications. Med Care. 1968;4:260-270.

32. Stewart MA. Effective physician-patient communication and health outcomes: A review. Can Med Assoc J. 1995;152:1423-1433.

33. Williams SJ, Calnan M. Key determinants of consumer satisfaction with general practice. Fam Pract. 1991;8:237-242.

34. Doubova SV, Torres-Arreola LP, Rosas-Carrasco O, Pérez-Cuevas R. Quality of medication prescribing for elderly patients with non-malignant pain syndrome attending to family medicine clinics. Rev Invest Clin. 2007;59:428-436.

35. Bensing JM, Dronkers J. Instrumental and affective aspects of physician behavior. Med Care. 1992;30:283-298.

36. Miedema K, Veltmaat LJ, Reenders K. Switching to insulin therapy in NIDDM patients. A study of inhibiting factors in family practice. Huisarts Wet. 1995;38:614-617.
37. Bradley C. Contributions of psychology to diabetes management. Br J Clin Psychol. 1994;33:11-21.

38. Figueroa JP, Ward E, Walters C, Ashley DE, Wilks RJ. High risk health behaviours among adult Jamaicans. West Indian Med J. 2005;54: 70-76.

39. Jackson JL, Chamberlin J, Kroenke K. Predictors of patient satisfaction. Soc Sci Med. 2001;52:609-620.

40. DiMatteo MR. Enhancing patient adherence to medical recommendations. JAMA. 1994;271:79-83.

41. Safran D, Taira D, Rogers WH, Kosinski M, Ware JE, Tarlov AR. Linking primary care performance to outcomes of care. J Fam Pract. 1998;47:213-220.

42. Wilks R, Younger N, Tulloch-Reid M, McFarlane S, Francis D. Jamaica health and lifestyle survey 2007-8: Technical Report. Kingston: Tropical Medicine Research Institute: The University of the West Indies; 2008 .

43. Waitzkin H. Clinical implications of social scientific research. JAMA. 1984;252:2441-2446.

44. Van Dongen N. Let's be effective, let the patients talk! Does 'patient intelligence' have an effect on improvements in quality within the health care environment? Patient Intelligence. 2009;1:1-5.

45. Clearly PD. The increasing importance of patient surveys. Now that sound methods exist, patient surveys can facilitate improvement. Br Med J. 1999;319:7201.

46. Tasa K, Baker T, Murray M. Using patient feedback for quality improvement. Qual Manag Health Care. 1996;4:55-67.

47. Vingerhoets E, Wensing M, Grol R. Feedback of patients' evaluations of general practice care: A randomised trial. Qual Health Care. 2001;10:224-228.

48. Wilcock PM, Brown GCT, Bateson J, Carver J, Machin S. Using patient stories to inspire quality improvement within the NHS Modernization Agency collaborative programmes. J Clin Nurs. 2003;12:422-430.
Patient Intelligence

\section{Publish your work in this journal}

Patient Intelligence is an international, peer-reviewed, open access journal that characterizes and measures the central role of patient behavior and intention in optimizing healthcare management in all areas of disease and complaint types. An improved understanding of patient intelligence coupled with predictive analysis helps an organization contribute more effectively to achieving better outcomes.

\section{Dovepress}

The journal is characterized by the rapid reporting of reviews, original research, methodologies, analytics, modeling, clinical studies and patient surveys across all disease areas. The manuscript management system is completely online and includes a very quick and fair peer-review system. Visit http://www.dovepress.com/ testimonials.php to read real quotes from published authors. 